\title{
The effect of repeated surface treatment of zirconia on its bond strength to resin cement
}

\author{
Lucas Campagnaro Maciel1', Marina Amaral'2, Daher Antonio Queiroz ${ }^{3}$, Kusai Baroudi*, \\ Laís Regiane Silva-Concílio ${ }^{2}$ \\ ${ }^{1}$ Postgraduate Program, School of Dentistry, University of Taubaté, Taubaté, Brazil \\ ${ }^{2}$ Department of Dental Prosthesis, School of Dentistry, University of Taubaté, Taubaté, Brazil \\ ${ }^{3}$ Division of Restorative and Prosthetic Dentistry, The Ohio State University College of Dentistry, Columbus, OH, USA
}

\begin{abstract}
PURPOSE. The aim of this study is to evaluate the influence of repeated surface treatments on wettability and surface roughness for zirconia surface and bond strength of zirconia-based ceramics to resin cement.

MATERIALS AND METHODS. Seventy blocks $(10 \times 10 \times 3 \mathrm{~mm})$ of zirconia-based ceramics were fabricated and divided into two groups according to the surface treatments: (A) $110 \mu \mathrm{m} \mathrm{Al} \mathrm{O}_{3}$ airborne-particle abrasion and (R) $110 \mu \mathrm{m}$ silica modified $\mathrm{Al}_{2} \mathrm{O}_{3}$ airborne-particle abrasion. At stage 2, each group was subdivided into 5 groups according to the surface retreatments: (a) $110 \mu \mathrm{m} \mathrm{Al}_{2} \mathrm{O}_{3}$ airborne-particle abrasion, (r) $110 \mu \mathrm{m}$ silica modified $\mathrm{Al}_{2} \mathrm{O}_{3}$ airborne-particle abrasion, (D) diamond bur, (Da) diamond bur $+110 \mu \mathrm{m} \mathrm{Al} \mathrm{O}_{3}$ airborne-particle abrasion, and (Dr) diamond bur $+110 \mu \mathrm{m}$ silica modified $\mathrm{Al}_{2} \mathrm{O}_{3}$ airborne-particle abrasion. Cylinders of self-adhesive resin cement were cemented onto each treated ceramic surface and subjected to micro-shear bond strength test. Additional specimens were prepared for roughness and wettability analyses. The data were subjected to t-test and One-way ANOVA followed by Tukey's post hoc test $(\alpha=.05)$. RESULTS. At stage 1 , group R presented higher bond strength values than group $\mathrm{A}(P=.000)$. There was a statistically significant increase of bond strength at stage 2 for group $\mathrm{A}(P=.003)$. The diamond bur influenced the surface roughness, increasing the values $(P=.023)$. Group R provided better wettability. Regardless of the applied surface treatment, most of failures were adhesive. CONCLUSION. The combination of application and reapplication of Rocatec Plus showed the best results of bond strength. Surface retreatment and recementation might be an indicated clinical strategy. [J Adv Prosthodont 2020;12:291-8]
\end{abstract}

KEYWORDS: Bond strength; Zirconia; Surface roughness; Wettability; Surface treatment

\section{INTRODUCTION}

The zirconia restorations have been widely utilized in oral rehabilitation dentistry and led to an increase on the clinical behavior research of this material. In a literature systematic review, Le et al. ${ }^{1}$ point out that the cumulative survival rates of these prostheses supported by teeth are $93.5 \%$. Despite

\section{Corresponding author:}

Kusai Baroudi

Associate Professor in the Postgraduate Program, School of Dentistry,

University of Taubaté, Rua dos Operários, 09- Centro, Taubaté - SP,

Brazil. CEP: 12020-330.

Tel. +55123629-2130: e-mail,d_kusai@yahoo.co.uk

Received March 10, 2020 / Last Revision June 15, 2020 / Accepted July

28,2020

(C) 2020 The Korean Academy of Prosthodontics

This is an Open Access article distributed under the terms of the Creative

Commons Attribution Non-Commercial License (http://creativecommons.

org/licenses/by-nc/4.0) which permits unrestricted non-commercial use,

distribution, and reproduction in any medium, provided the original

work is properly cited. zirconia-based ceramics has excellent mechanical properties to be used in higher occlusal load regions when compared to other ceramic systems like lithium disilicate, ${ }^{2,3}$ it has physico-chemical features that affect their low performance in terms of adhesion at different substrates. Furthermore, the incidence of loss of retention of these crowns is significantly higher when compared to other ceramics. ${ }^{4,5}$ The most commonly noticed failures when using this material are structure fracture, chipping of the veneering ceramic, aesthetic discontent of the patients, and loss of retention. ${ }^{1,3,6-8}$

In a clinical follow-up study of the overall outcome of cemented zirconia crowns on teeth, Örtorp et al. ${ }^{9}$ found a clinical complication rate of $16 \%$ after 3 years follow-up and that $7 \%$ of these complications were loss of retention; from 12 debonded restorations, eight could be recemented. Schmitter et al. ${ }^{6}$ found in their five years follow-up study that of twenty-two extensive fixed partial denture zirconia, four presented loss of retention and were recemented. Rinke et $a l^{8}$ pointed out that after a 10 -year clinical observa- 
tion period, out of 99 fixed partial dentures of 3 and 4 zirconia-based units, only 13 had technical failures and 5 of these were associated with loss of retention.

After adhesive failure, when the integrity of the abutment and the restoration are noticed, as well as the ideal fitting of the restoration to the prepared tooth, the recementation is a clinical viable solution, providing financial and time savings to the professional and patient. ${ }^{10,11}$ For this reason, a new surface treatment is recommended for both of the crown and the abutment, in order to remove possible remnants of cementing agent, in addition to promoting satisfactory adhesive interface substrates. ${ }^{12,13}$

Although the possibility that the recementation technique seems to be a reasonable strategy compatible with clinical reality, ${ }^{6,9}$ it is important to consider the damage risk to the ceramic structure during the retreatment of its surface. The success of this strategy is directly related to obtaining an adequate adhesive surface (with adequate roughness and wettability, which are highly relevant for bond strength) after retreatment of the substrates involved in the interface, providing satisfactory bond strength results. From the knowledge of the authors, no clinical or in vitro data is available on the survival rate, bond strength values, and surface characteristics of recemented zirconia prosthetic pieces. This clinical dynamics of surface retreatment and recementation without damage of the bond strength still needs to be better understood.

The aim of the study was to evaluate the influence of the surface retreatment and recementation on the bond strength of zirconia-based ceramics/self-adhesive resin cement interface, as well as the influence of surface retreatment on the wettability and surface roughness of the ceramic. The null hypotheses are that the surface retreatments preceding the recementation do not change the bond strength of the self-adhesive resin cement/zirconia-based ceramic system interface. In addition, surface retreatments do not influence surface roughness and wettability.

\section{MATERIALS AND METHODS}

Seventy zirconia-based ceramics blocks (Zirkon Prettau, Zirkonzahn $\mathrm{GmbH}$, Gais, Italy) were randomly distributed into 2 groups according to the surface: Group A - airborneparticle abrasion and Group R - silica-coated (Rocatec Plus System, Seefeld, Germany). Four cylinders of resin cement (Rely X U200, 3M ESPE, Seefeld, Germany) were cemented onto each treated block and subjected to the micro-shear bond strength test (stage 1). Thereafter, to perform the cementation of the new specimens and new micro-shear bond strength test (stage 2), each group was subdivided into 5 groups $(\mathrm{n}=7)$ according to the second surface treatment: airborne-particle abrasion (a), silica coated (r), diamond bur (D), diamond bur + airborne-particle abrasion (Da), and diamond bur + silica coated (Dr). Additional specimens were prepared to analyze the surface roughness and wettability after surface treatments proposed in the study. All steps (specimens, bonding and analysis) were completed by one individual for consistency (Fig. 1 and Table 1).
TIME 1

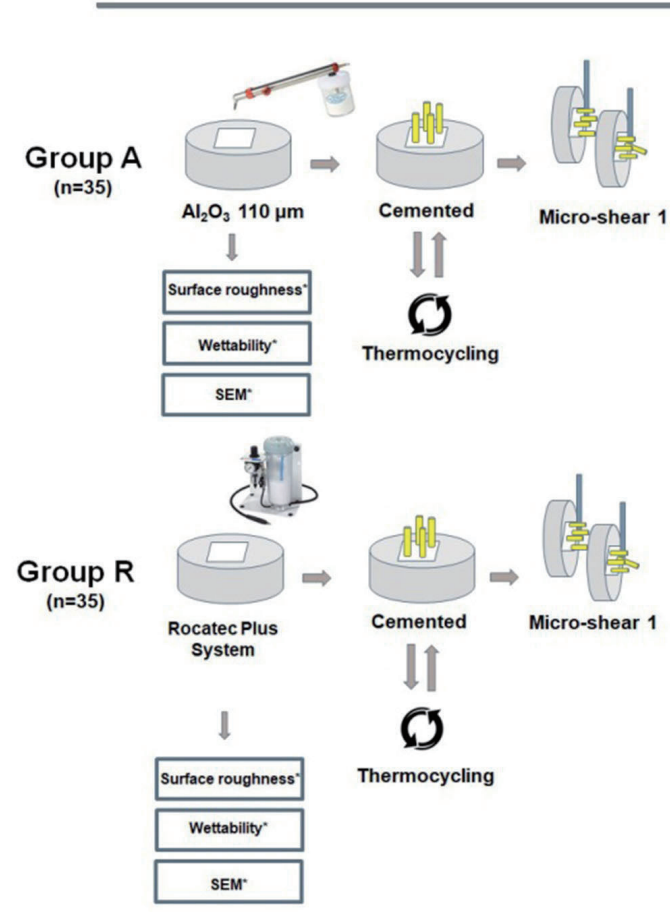

TIME 2

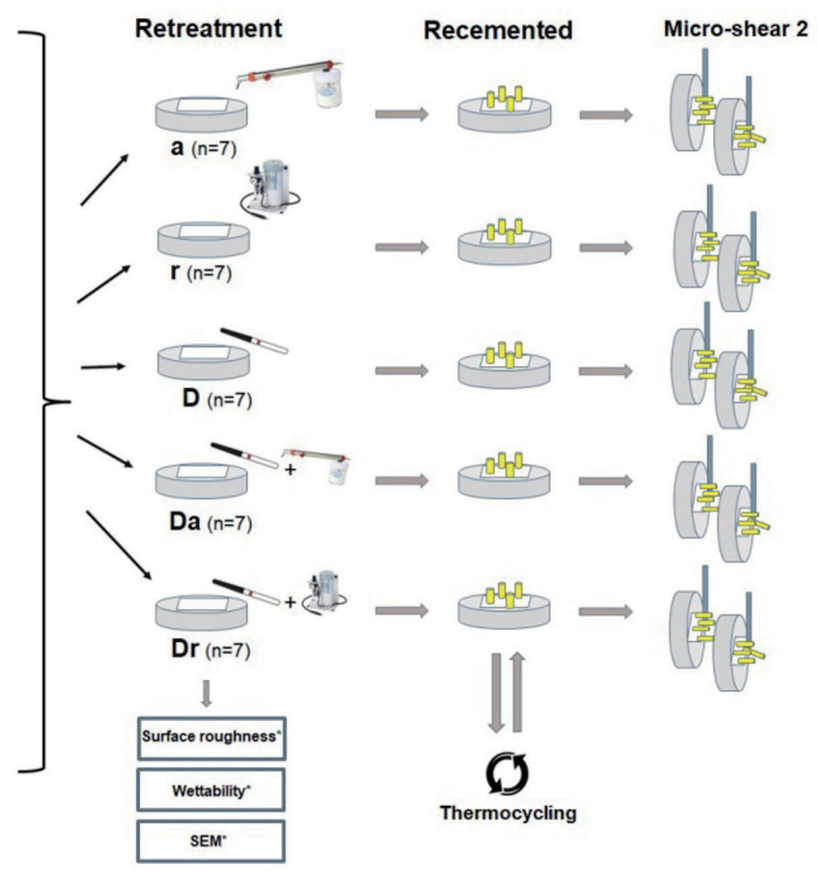

Fig. 1. Study flowchart. * Analysis performed on additional samples. 
Table 1. Materials used in this study

\begin{tabular}{|c|c|c|}
\hline Materials & Composition & Manufacturer \\
\hline Ceramics & $\begin{array}{l}\text { Yttria partially stabilized tetragonal zirconia (Zirconia Y-TZP based } \\
\text { ceramics): Zirconia oxide } 97 \% \text {, Yttrium oxide 3\% }\end{array}$ & $\begin{array}{l}\text { Zirkon Prettau, Zirkonzahn GmbH, } \\
\text { Gais, Italy }\end{array}$ \\
\hline Self-adhesive resin cement & $\begin{array}{l}\text { Base paste: Methacrylate monomers containing phosphoric acid groups, } \\
\text { Methacrylate monomers, Silanated fillers, Initiator components, } \\
\text { Stabilizers, Rheological additives } \\
\text { Catalyst paste: Methacrylate monomers, Alkaline fillers, Silanated fillers, } \\
\text { Initiator components, Stabilizers, Pigments, Rheological additives }\end{array}$ & $\begin{array}{l}\text { Rely X U200, 3M ESPE, Seefeld, } \\
\text { Germany }\end{array}$ \\
\hline Diamond bur & Diamond bur coated with $46 \mu \mathrm{m}$ diamond grain & KG Sorensen, Cotia, Brazil \\
\hline $\mathrm{Al}_{2} \mathrm{O}_{3}$ particle & $110 \mu \mathrm{m}$ aluminum oxide particle & $\begin{array}{l}\text { Bio-Art Equip Odontol Ltd., } \\
\text { São Carlos, Brazil }\end{array}$ \\
\hline Sillica modifiend $\mathrm{Al}_{2} \mathrm{O}_{3}$ particle & $110 \mu \mathrm{m}$ silica/alumina particles & $\begin{array}{l}\text { Rocatec Plus, 3M-ESPE, Seefeld, } \\
\text { Germany }\end{array}$ \\
\hline Silane & (MPS) 3-methacryloyloxypropyl trimethoxysilane; ethanol, water & $\begin{array}{l}\text { RelyX Ceramic Primer, 3M-ESPE, } \\
\text { Seefeld, Germany }\end{array}$ \\
\hline
\end{tabular}

Sample size was estimated based on previous literatures. ${ }^{14,15}$ Data were subjected to t-Studant's test for independent samples, with 5\% significance level, and 90\% power. The results indicate a sample size of $7(\mathrm{n}=7)$ with $10 \%$ safety margin. Seventy $(10 \times 10 \times 3 \mathrm{~mm})$ monolithic zirconia-based ceramics blocks (Zirkon Prettau, Zirkonzahn $\mathrm{GmbH}$, Gais, Italy) were obtained using an electrical high precision cutter (Isomet, Buehler Ltd., Lake Buff, IL, USA) and were polished with silicon carbide abrasive paper (\# 600, Norton, Guarulhos, Brazil). Thereafter, the specimens were sintered following the manufacturer's instructions. For inclusion, the ceramic blocks were adapted into clear plastic container (Tubes, Tigre, Joinville, Brazil) and epoxy resin (Valglass, São José dos Campos, Brazil) were poured into it. The standardization of the surfaces of the samples was carried out using wet silicon carbide abrasive paper (\# 200, \# 400 and \# 600, Norton).

At stage 1, zirconia surface treatment of group A was carried out with $110 \mu \mathrm{m}$ aluminum oxide $\left(\mathrm{Al}_{2} \mathrm{O}_{3}\right)$ airborneparticle abrasion (Bio-Art Equip Odontol Ltd., São Carlos, Brazil) perpendicular to the adhesive surface with $0.28 \mathrm{MPa}$ pressure at $10 \mathrm{~mm}$ distance, during 10 seconds. For the $\mathrm{R}$ group, silica-coated using the Rocatec Plus system (Rocatec Plus, 3M-ESPE, Seefeld, Germany) was blasted perpendicular to the adhesive surface, with $0.28 \mathrm{Mpa}$ pressure at 10 $\mathrm{mm}$ distance for 15 seconds. All specimens were cleaned in distilled water for 3 minutes in an ultrasonic bath (ultrasonic tub, Cristófoli Equipamentos de Biosseguraça, Campo Mourão, Brazil) and dried out. In R group, silane (RelyX Ceramic Primer, 3M-ESPE, Seefeld, Germany) was applied for $20 \mathrm{~s}$.

For the surface roughness and wettability ceramic analysis at stage 1, 21 additional specimens were made as previously described. Seven did not receive any treatment (control group) and the others were divided into two groups according to the described surface treatments (stage 1). The specimens were first subjected to cleaning in ultrasonic bath, immersed into distilled water (180 s), and then the surface roughness $(\mathrm{Ra})$ of each specimen was measured, in micrometers, with a profilometer (Surftest 301, Mitutoyo, Sakado, Japan) previously calibrated. Three parallel readings ( $4 \mathrm{mN}$, range of $0.8 \mathrm{~mm}$, at $0.25 \mathrm{~mm} / \mathrm{s}$ ) of each surface were recorded, and the average was calculated. ${ }^{16}$

The wettability was evaluated through the contact angle analysis by the sessile drop technique. One drop of distilled water was placed on the surface of the ceramic with the aid of a pre-defined drop account to release $11 \mu \mathrm{L}$ of distilled water adapted to the goniometer (Ramé-Hart - DROP image, Advanced). A goniometer image processing software calculated, after $5 \mathrm{~s}$, the contact angle produced by the drop. The mean of 3 measurements was calculated for each specimen. ${ }^{17,18}$

Four cylinders $(1.2 \mathrm{~mm}$ diameter $\times 2.0 \mathrm{~mm}$ high $)$ of self-adhesive resin cement (Rely X U200, 3M ESPE, Seefeld, Germany) were cemented using a transparent matrix (Tygon tubing, TYG-030, Saint-Gobain Performance Plastic, Paris, France) for each ceramic block. According to the manufacturer's instructions, the cement was prepared and inserted (Centrix syringe, DFL Indústria e Comércio, Rio de Janeiro, Brazil), inside the previously matrix positioned on the ceramic surface and cured for $20 \mathrm{~s}$ by photopolymerizer (Bluephase N, Ivoclar Vivadent, Schaan, Liechtenstein) at $1,100 \mathrm{~mW} / \mathrm{cm}^{2}$ power density perpendicular to the ceramic surface. After cementation, the samples were packed in a plastic container and immersed in distilled water and stored (Incubator, Quimis Científica Equipamentos Ltd., Diadema, Brazil) with a controlled temperature of 37 $\pm 1^{\circ} \mathrm{C}$. Before the micro-shear bond strength test, all specimens were thermocycled (Thermocycling equipment, Biopdi, São Carlos, Brazil) in distilled water between $5^{\circ} \mathrm{C}$ and $55^{\circ} \mathrm{C}$ for 3000 cycles, ${ }^{14}$ with a dwell time of $30 \mathrm{~s}$ in each bath. 
Micro-shear bond strength test at stage 1 was performed by loading the cementation line by a chisel attached to the top of the universal test machine (Shimadzu AG-X, Shimadzu Corporation, Kyoto, Japan) and a force with a load cell corresponding to $1 \mathrm{kN}$ was applied to the adhesive interface at a constant crosshead speed of $0.5 \mathrm{~mm}$ per minute until failure. The values required for union rupture (bond strength) were recorded in MPa by the software (Trapezium-X Software, Shimadzu Corporation, Kyoto, Japan).

After micro-shear bond strength test, the debonded surfaces were examined under a stereomicroscope evaluated at $10 \times$ magnification (Aus Jena, Carl Zaiss, Oberkochen, Germany) by a single trained observer. The failure mode was determined as 'adhesive' when the fracture occurred only on the ceramic surface, 'cohesive' when there was only fracture in the cement material, and 'mixed' when presented the two types of failure.

At stage 2, the specimens of groups $A$ and $R$ (stage 1) were subdivided into five new groups $(\mathrm{n}=7)$ according to the new surface treatments: (a) $110 \mu \mathrm{m} \mathrm{Al}_{2} \mathrm{O}_{3}$ airborne-particle abrasion, (r) Rocatec Plus system, (D) diamond bur, (Da) diamond bur $+110 \mu \mathrm{m} \mathrm{Al}_{2} \mathrm{O}_{3}$ airborne-particle abrasion, and (Dr) diamond bur + Rocatec Plus. Procedures for airborne-particle abrasion and silica-coating (Rocatec Plus, 3M ESPE, Seefeld, Germany) were performed as previously described. For the adjustment of the ceramic surface with diamond bur (D), $46 \mu \mathrm{m}$ fine grain diamond burs (\# 3195F, KG Sorensen, Cotia, Brazil) were used at 20,000 rpm under digital pressure and water cooling during $30 \mathrm{~s}$. All samples were cleaned in ultrasonic tub with distilled water for $3 \mathrm{~min}$ and dried out for $20 \mathrm{~s}$. For the groups that received Rocatec Plus as final treatment, silane was applied as described previously.

Seventy additional samples were prepared as previously described and divided into ten groups $(\mathrm{n}=7)$. Surface roughness and wettability evaluation at stage 2 were performed according to methods previously described. New resin cement cylinders were made and thermocycled (3000 cycles) as previously described.

Micro-shear bond strength test and debonded surface analysis were done (stage 2).

The specimens were then submitted to the second micro-shear bond strength test and the debonded surfaces were analyzed according to the previously described methods, and subjected to failure analysis as described before.

Representative specimens of each group were given specific treatment (surface metallization) to be evaluated in scanning electron microscopy (SEM) (Inspect S50 2011, FEI Company, Hillsboro, OR, USA).

The bond strength (BS) data, mean surface roughness, and contact angle were subjected to the KolmogorovSmirnov normality test $(\alpha=.05)$. In the comparison of BS at stage 1 , the t-test $(\alpha=.05)$ was used at stage 2, One-Way ANOVA test followed by Tukey's post hoc test $(\alpha=.05)$ was used. To compare the BS between stages 1 and 2, the t-paired test was applied $(\alpha=.05)$. For both the surface roughness data and the contact angle data, one-way ANOVA followed by Tukey's post hoc test $(\alpha=.05)$ was applied. For statistical analysis, the biostatistical software (Bioestat 5.0, Bioestat, Mamiruá Institute, Tefé, Brazil) was used. SEM images were submitted to descriptive analysis.

\section{RESULTS}

Table 2 presents the mean bond strength values and respective standard deviations of the tested groups according to the different surface treatments at stages 1 and 2. At stage 1, airborne particle abrasion with silica modified $\mathrm{Al}_{2} \mathrm{O}_{3}$ particles $(\mathrm{R})$ showed the highest shear bond strength values $(P=$ .000). At stage 2 (the recementation procedure), group (A) retreated groups, which received airborne particle abrasion with silica modified $\mathrm{Al}_{2} \mathrm{O}_{3}$ particles ( $\mathrm{r}$ ) and not diamond bur, presented the highest bond strength values $(P=.003)$. In the same way, at stage 1, $(\mathrm{R})$ retreated groups with (r) presented the highest bond strength values $(P=.000)$.

Comparing groups $\mathrm{A}$ and $\mathrm{R}$ at stage 1 and at stage 2, bond strength was enhanced when group (A) received retreatment $(P=.000)$, and values were kept when $\mathrm{R}$ received retreatment $(P=.495)$ (Fig. 2).

Table 3 shows the average values at surface roughness measured in each of the treatments and each of the treatments plus retreatments of zirconia-based ceramic. There was a significant difference in surface roughness between surface treatments performed at stage $1(P=.023)$, but after retreatment (stage 2), zirconia surface was rougher after diamond abrasion, despite the surface treatment applied previously at stage 1 .

Table 2. Mean bond strength values and standard deviations (MPa) of the groups evaluated according to surface treatment and cementation stage

\begin{tabular}{|c|c|c|c|}
\hline \multicolumn{2}{|r|}{ Stage 1} & \multicolumn{2}{|r|}{ Stage 2} \\
\hline Groups & Bond Strength (MPa) & Groups & Bond Strength (MPa) \\
\hline \multirow{5}{*}{ A } & \multirow{5}{*}{$8.3(1.1)$} & $\mathrm{Aa}$ & $11.9(1.2)^{\mathrm{BC}}$ \\
\hline & & $\mathrm{Ar}$ & $14.0(2.0)^{A B C}$ \\
\hline & & $A D$ & $11.8(1.7)^{\mathrm{C}}$ \\
\hline & & Ada & $14.5(1.7)^{\mathrm{AB}}$ \\
\hline & & $\mathrm{ADr}$ & $14.9(1.8)^{\mathrm{A}}$ \\
\hline \multirow{7}{*}{$\mathrm{R}$} & & & $P=.003$ \\
\hline & \multirow{5}{*}{$14.1(1.2)$} & $\mathrm{Ra}$ & $12.90(1.5)^{\mathrm{B}}$ \\
\hline & & $\mathrm{Rr}$ & $16.7(3.0)^{\mathrm{A}}$ \\
\hline & & $\mathrm{RD}$ & $11.7(1.4)^{\mathrm{B}}$ \\
\hline & & $\mathrm{RDa}$ & $13.5(1.3)^{\mathrm{B}}$ \\
\hline & & $\mathrm{RDr}$ & $13.8(0.9)^{\mathrm{B}}$ \\
\hline & $P=.023$ & & $P=.000$ \\
\hline
\end{tabular}

*Different superscript letters indicate statistical difference between same halfcolumn in stage 2. 


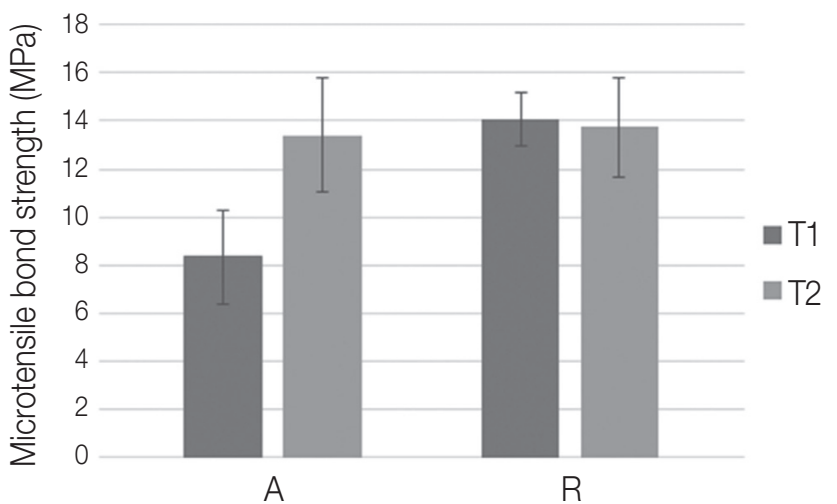

Fig. 2. Mean bond strength values and standard deviations (MPa) of Group A - airborne-particle abrasion and Group R - silica-coated (Rocatec Plus System) at stage 1 and stage 2 .

Table 3. Mean surface roughness values and standard deviations $(\mu \mathrm{m})$ of the groups evaluated according to surface treatment and cementation stage

\begin{tabular}{|c|c|c|c|}
\hline \multicolumn{2}{|r|}{ Stage 1} & \multicolumn{2}{|r|}{ Stage 2} \\
\hline Groups & Surface roughness ( $\mu \mathrm{m})$ & Groups & Surface roughness $(\mu \mathrm{m})$ \\
\hline \multirow{5}{*}{$A$} & \multirow{5}{*}{$0.21(0.01)$} & $\mathrm{Aa}$ & $0.23(0.02)^{c}$ \\
\hline & & $\operatorname{Ar}$ & $0.24(0.03)^{\mathrm{C}}$ \\
\hline & & $A D$ & $0.57(0.03)^{A}$ \\
\hline & & $\mathrm{ADa}$ & $0.48(0.02)^{\mathrm{B}}$ \\
\hline & & ADr & $0.53(0.04)^{A B}$ \\
\hline \multirow{7}{*}{$\mathrm{R}$} & \multirow{6}{*}{$0.24(0.03)$} & \multicolumn{2}{|r|}{$P=.000$} \\
\hline & & $\mathrm{Ra}$ & $0.22(0.03)^{c}$ \\
\hline & & $\operatorname{Rr}$ & $0.23(0.04)^{c}$ \\
\hline & & $\mathrm{RD}$ & $0.62(0.02)^{A}$ \\
\hline & & $\mathrm{RDa}$ & $0.55(0.04)^{\mathrm{B}}$ \\
\hline & & $\mathrm{RDr}$ & $0.52(0.02)^{\mathrm{B}}$ \\
\hline & $P=.023$ & \multicolumn{2}{|r|}{$P=.000$} \\
\hline
\end{tabular}

*Different superscript letters indicate statistical difference between same halfcolumn in stage 2.

Contact angle was also affected by treatment and retreatment of zirconia surface (Table 4). It was greater for A at stage 1. Contact angle was also affected in stage 2.

With scanning electron microscopy (SEM), we observed the patterns of surface irregularities in the groups submitted to treatment and retreatment with Rocatec Plus and $110 \mu \mathrm{m}$ $\mathrm{Al}_{2} \mathrm{O}_{3}$, as well as groove imaging caused by surface adjustment with the diamond bur and smoothing when combined with Rocatec Plus and $110 \mu \mathrm{m} \mathrm{Al} \mathrm{O}_{3}$ (Fig. 3).
Table 4. Mean contact angle values and standard deviations of the groups evaluated according to surface treatment

\begin{tabular}{|c|c|c|c|}
\hline \multicolumn{2}{|r|}{ Stage 1} & \multicolumn{2}{|c|}{ Stage 2} \\
\hline Groups & Contact angle & Groups & Contact angle \\
\hline \multirow{5}{*}{ A } & \multirow{5}{*}{$61.4(4.6)$} & $\mathrm{Aa}$ & $65.1(3.4)^{\mathrm{A}}$ \\
\hline & & $\mathrm{Ar}$ & $54.4(3.9)^{\mathrm{B}}$ \\
\hline & & $A D$ & $63.1(3.0)^{\mathrm{A}}$ \\
\hline & & $\mathrm{ADa}$ & $68.1(3.7)^{\mathrm{A}}$ \\
\hline & & ADr & $52.2(4.1)^{\mathrm{B}}$ \\
\hline \multirow{7}{*}{$\mathrm{R}$} & \multirow{6}{*}{$50.8(2.1)$} & \multicolumn{2}{|c|}{$P=.000$} \\
\hline & & $\mathrm{Ra}$ & $59.5(2.9)^{\mathrm{A}}$ \\
\hline & & $\mathrm{Rr}$ & $64.1(2.8)^{A}$ \\
\hline & & $\mathrm{RD}$ & $62.4(2.9)^{\mathrm{A}}$ \\
\hline & & $\mathrm{RDa}$ & $60.1(4.4)^{\mathrm{A}}$ \\
\hline & & $\mathrm{RDr}$ & $49.8(2.3)^{\mathrm{B}}$ \\
\hline & $P=.001$ & \multicolumn{2}{|c|}{$P=.000$} \\
\hline
\end{tabular}

*Different superscript letters indicate statistical difference between same halfcolumn in stage 2 .

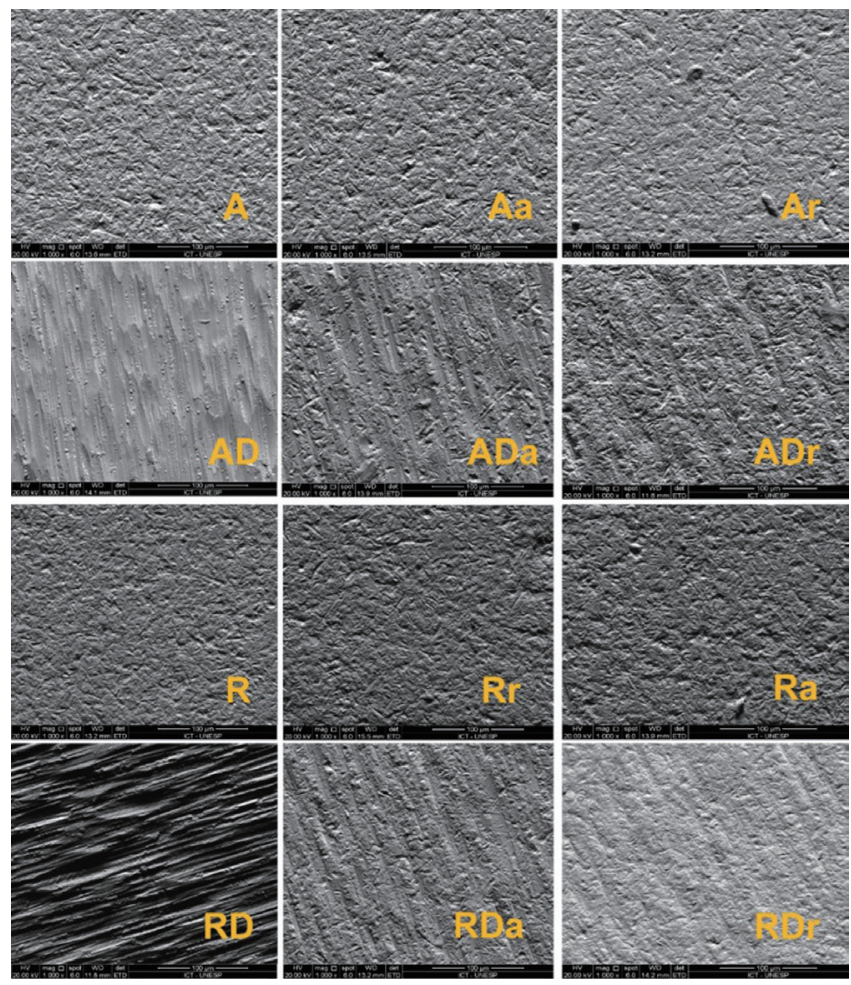

Fig. 3. It is observed that the application of the diamond bur both after $\mathrm{Al}_{2} \mathrm{O}_{3}(\mathrm{~A})$ and Rocatec Plus (R) produced greater irregularities (AD and $\mathrm{RD}$ ). The sequential reapplication of both $\mathrm{Al}_{2} \mathrm{O}_{3}$ and Rocatec Plus to samples previously adjusted with the diamond bur has been shown to smooth out surface irregularities (ADa, ADr, RDa and RDr). 
120

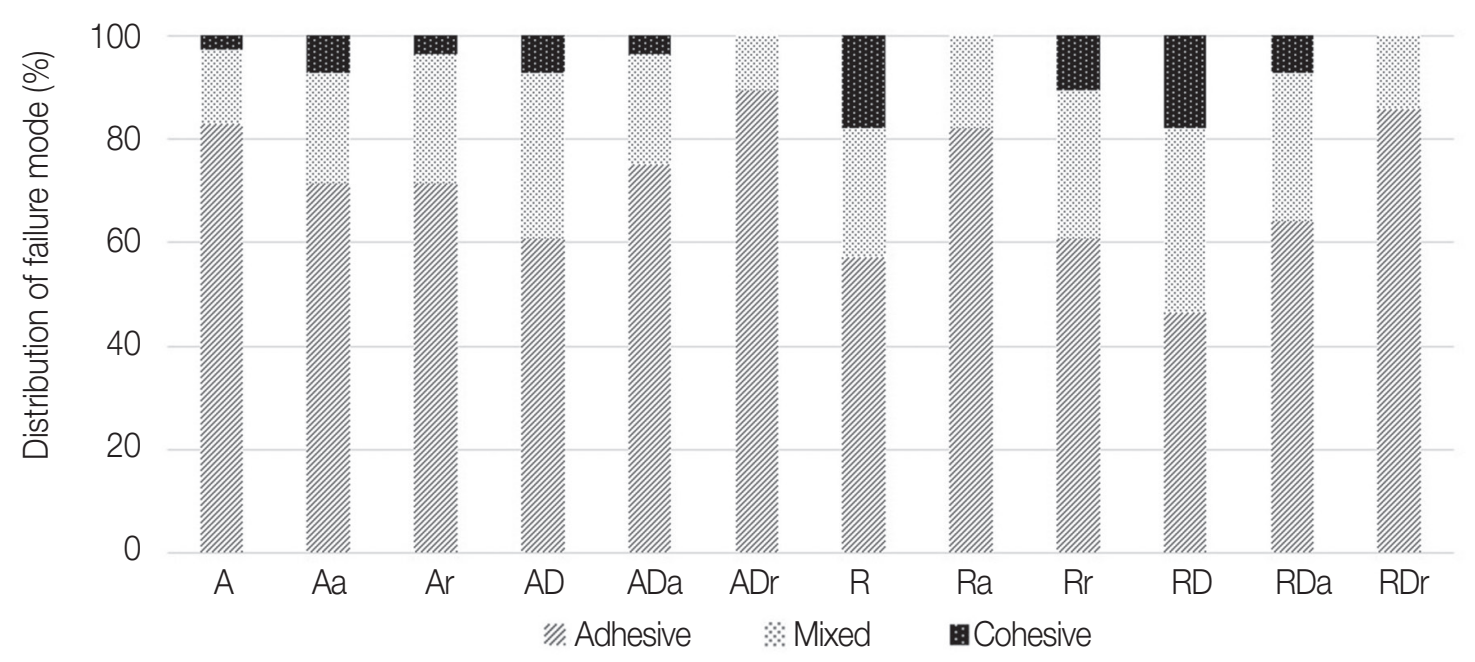

Fig. 4. Failure modes according to the tested group.

Fig. 4 shows the percentages of failure mode (adhesive, mixed and cohesive). Regardless of the applied surface treatment, most of the failures were adhesive. When the 110 $\mu \mathrm{m} \mathrm{Al}_{2} \mathrm{O}_{3}$ airborne-particle abrasion was chosen at stage 1 , except for the ADr group, an increase in mixed and cohesive failure at stage 2 could be observed. When Rocatec Plus was used as a surface treatment in the stage 1, with the exception of the RD group, there was an increase of adhesive failure at stage 2 .

\section{DISCUSSION}

The results presented in this study show that both null hypotheses were rejected. When $110 \mu \mathrm{m} \mathrm{Al}_{2} \mathrm{O}_{3}$ airborneparticle abrasions were adopted as the initial surface treatment, regardless of the proposed retreatment, there was an increase in bond strength after the recementation. However, when Rocatec Plus was used, only the groups where this strategy was used at stage 2 kept the shear bond strength similar to initial stage, and the other groups presented a decrease in the shear bond strength. Furthermore, the use of the diamond bur provided an increase in surface roughness, regardless of the initial surface treatment, and Rocatec Plus increased wettability when used as surface retreatment of the specimens subjected to initial $\mathrm{Al}_{2} \mathrm{O}_{3}$ airborne-particle abrasion. Appropriate dental preparation provides nice retention and stability, but the use of milled crowns such as zirconia-based ceramics requires the interposition of a thick layer of cement, which assumes a fundamental role in the interaction with the ceramics (adhesion) to achieve clinical success. ${ }^{19,20}$

However, the loss of zirconia crown retention is an inherent intercurrence with this restoration material. ${ }^{1,9}$ Whenever possible, the surfaces retreatment that involved adhesive interface and the crown recementation are adopted in clinical practices aiming at the clinical longevity. ${ }^{10-13}$

The strategy used in this in vitro study simulated a clinical situation, in which in the first stage, the surface treatment and bonding of an indirect zirconia restoration were performed using self-adhesive resin cement and in the second stage, the surface retreatment and recementing of the same indirect restoration were performed.

Micromechanical retention by blasting with aluminum oxide particles is important for the bond strength between zirconia and resin cement. ${ }^{15,21-23}$ In addition, previous studies $^{24-26}$ showed that phosphate monomers (MDP) available in some of the cements have the potential to establish chemical bond properties with metallic oxides present on the surface of zirconia supporting adhesion. Some authors ${ }^{27,28}$ suggest that zirconia-based ceramic surface blasted with silica provides a layer that the silane interacts to create a strong and stable chemical bond with the resin cements. Sciasci et al..$^{15}$ demonstrate that Rocatec Plus with subsequent silane yields a bond strength to the resin cement higher than that provided by zirconia-based ceramic surface blasting with $\mathrm{Al}_{2} \mathrm{O}_{3}$ particles of $120 \mu \mathrm{m}$ and the results of the present study (stage 1) corroborate those findings.

In the present study, it was observed that the surface retreatments positively influenced the bond strength when the $\mathrm{Al}_{2} \mathrm{O}_{3}$ airborne-particle abrasion was used for initial cementation and negatively influenced when the Rocatec Plus was used initially. The authors hypothesis is that $\mathrm{Al}_{2} \mathrm{O}_{3}$ airborne-particle abrasion promotes the removal of the residual resin cement and the formation of sites for micromechanical retention. Moreover, it may also be able to remove the residual silica particles from previous application of Rocatec Plus, affecting chemical adhesion and consequently resulting in a decrease in bond strength. 
The ceramics wettability and surface roughness are factors directly associated with adhesion and determinants for excellent clinical results. ${ }^{29}$ Pazinatto et al. ${ }^{30}$ describe that rougher surfaces expand the areas available for adhesion, providing an increased free surface energy, consequently promoting wettability. However, Yamaguchi et al. ${ }^{31}$ stated that although the zirconia-based ceramics treated by sandblasting with silica-coated had lower surface roughness values than those with $\mathrm{Al}_{2} \mathrm{O}_{3}$ particles, the silica coating provided the highest values of free surface energy. According to the authors, the silica coating makes this layer hydrophilic, increasing the wettability. A similar fact could be observed in the present study, in which the lower values of the contact angle and, consequently, better wettability were presented by the groups that received Rocatec Plus as the final surface treatment strategy, regardless of the roughness.

As mentioned in the literature, ${ }^{32,33}$ it is possible to observe in the present study a predominance of adhesive failures independent of the surface treatment strategy adopted (Fig. 4). These results support the understanding of the limitations of adhesion between zirconia-based ceramics and resin cement. Shear bond strength test presents unequal stress distribution in the adhesive interface, ${ }^{34}$ leading to cohesive failure in the bottom half of the adhesive interface, where compression stress is developed. Thus, the failure mode is not related to the bond strength values (i.e. adhesive failures related to low bond strength values or cohesive failures related to high bond strength values).

Within the parameters adopted for this in vitro study, the obtained results showed that the surface retreatment and recementation strategy were satisfactory for a possible clinical indication and most of the time without burden to the bong strength. The exact positioning of the resin cement cylinder at the second stage was a challenge and might be the limitation of the present study. Also, the roughness measurement was performed by three parallel readings in only one direction; different reading settings, as 3 measurements in one direction and 3 measurements in a perpendicular direction, could have presented different results. Finally, it is worth mentioning that more studies on this subject still need to be carried out for further discussions and consolidation of the findings.

\section{CONCLUSION}

The use of Rocatec Plus as a strategy for surface retreatment provides results similar or better to those achieved in the initial cementation. However, reapplication of $110 \mu \mathrm{m}$ $\mathrm{Al}_{2} \mathrm{O}_{3}$ airborne-particle abrasion and Rocatec Plus did not change surface roughness. Rocatec Plus provided lower contact angle values and consequently better wettability. Further studies should be conducted to test other hypotheses related to this subject to define the best protocol to be used. But within the parameters used in this vitro study, the combination of the application and reapplication of Rocatec Plus showed the best results to the bond strength. It can be concluded that this surface retreatment (Rocatec Plus) and rece- mentation protocol used in this vitro study may be a possible clinical indication.

\section{ORCID}

Lucas Campagnaro Maciel bttps://orid.org/0000-0002-7687-4535

Marina Amaral https://orcid.org/0000-0002-4301-2760

Daher Antonio Queiroz https://orcid.org/0000-0002-1477-8599

Kusai Baroudi bttps://orcid.org/0000-0002-1009-0869

Laís Regiane Silva-Concilio bttps://orcid.org/0000-0002-3054-3810

\section{REFERENCES}

1. Le M, Papia E, Larsson C. The clinical success of tooth- and implant-supported zirconia-based fixed dental prostheses. A systematic review. J Oral Rehabil 2015;42:467-80.

2. Koenig V, Vanheusden AJ, Le Goff SO, Mainjot AK. Clinical risk factors related to failures with zirconia-based restorations: an up to 9-year retrospective study. J Dent 2013;41:1164-74.

3. Cantner F, Cacaci C, Mücke T, Randelzhofer P, Hajtó J, Beuer F. Clinical performance of tooth- or implant-supported veneered zirconia single crowns: 42-month results. Clin Oral Invest 2019;23:4301-9.

4. Pjetursson BE, Sailer I, Makarov NA, Zwahlen M, Thoma DS. All-ceramic or metal-ceramic tooth-supported fixed dental prostheses (FDPs)? A systematic review of the survival and complication rates. Part II: Multiple-unit FDPs. Dent Mater 2015;31:624-39.

5. Sailer I, Makarov NA, Thoma DS, Zwahlen M, Pjetursson BE. All-ceramic or metal-ceramic tooth-supported fixed dental prostheses (FDPs)? A systematic review of the survival and complication rates. Part I: Single crowns (SCs). Dent Mater 2015;31:603-23.

6. Schmitter M, Mussotter K, Rammelsberg P, Gabbert O, Ohlmann B. Clinical performance of long-span zirconia frameworks for fixed dental prostheses: 5-year results. J Oral Rehabil 2012;39:552-7.

7. Dogan S, Raigrodski AJ, Zhang H, Mancl LA. Prospective cohort clinical study assessing the 5-year survival and success of anterior maxillary zirconia-based crowns with customized zirconia copings. J Prosthet Dent 2017;117:226-32.

8. Rinke S, Wehle J, Schulz X, Bürgers R, Rödiger M. Prospective evaluation of posterior fixed zirconia dental prostheses: 10-year clinical results. Int J Prosthodont 2018;31:35-42.

9. Örtorp A, Kihl ML, Carlsson GE. A 3-year retrospective and clinical follow-up study of zirconia single crowns performed in a private practice. J Dent 2009;37:731-6.

10. St Germain HA Jr, St Germain TH. Shear bond strength of porcelain veneers rebonded to enamel. Oper Dent 2015;40: E112-21.

11. Kern M, Passia N, Sasse M, Yazigi C. Ten-year outcome of zirconia ceramic cantilever resin-bonded fixed dental prostheses and the influence of the reasons for missing incisors. J Dent 2017;65:51-5.

12. Martins ME, Leite FP, Queiroz JR, Vanderlei AD, Reskalla $\mathrm{HN}$, Ozcan M. Does the ultrasonic cleaning medium affect the adhesion of resin cement to feldspathic ceramic?. J Adhes 
Dent 2012;14:507-9.

13. Granell-Ruíz M, Agustín-Panadero R, Fons-Font A, RománRodríguez JL, Solá-Ruíz MF. Influence of bruxism on survival of porcelain laminate veneers. Med Oral Patol Oral Cir Bucal 2014;19:e426-32.

14. Amaral M, Belli R, Cesar PF, Valandro LF, Petschelt A, Lohbauer U. The potential of novel primers and universal adhesives to bond to zirconia. J Dent 2014;42:90-8.

15. Sciasci P, Abi-Rached FO, Adabo GL, Baldissara P, Fonseca RG. Effect of surface treatments on the shear bond strength of luting cements to Y-TZP ceramic. J Prosthet Dent 2015;113:212-9.

16. Akar GC, Pekkan G, Çal E, Eskitaşçıŏlu G, Özcan M. Effects of surface-finishing protocols on the roughness, color change, and translucency of different ceramic systems. J Prosthet Dent 2014;112:314-21.

17. Venturini AB, Prochnow C, Rambo D, Gundel A, Valandro LF. Effect of hydrofluoric acid concentration on resin adhesion to a feldspathic ceramic. J Adhes Dent 2015;17:313-20.

18. Prado M, Prochnow C, Marchionatti AME, Baldissara P, Valandro LF, Wandscher VF. Ceramic surface treatment with a single-component primer: Resin adhesion to glass ceramics. J Adhes Dent 2018;20:99-105.

19. Peutzfeldt A, Sahafi A, Flury S. Bonding of restorative materials to dentin with various luting agents. Oper Dent 2011;36:266-73.

20. Qeblawi DM, Campillo-Funollet M, Muñoz CA. In vitro shear bond strength of two self-adhesive resin cements to zirconia. J Prosthet Dent 2015;113:122-7.

21. Wolfart M, Lehmann F, Wolfart S, Kern M. Durability of the resin bond strength to zirconia ceramic after using different surface conditioning methods. Dent Mater 2007;23:45-50.

22. Ozcan M, Nijhuis H, Valandro LF. Effect of various surface conditioning methods on the adhesion of dual-cure resin cement with MDP functional monomer to zirconia after thermal aging. Dent Mater J 2008;27:99-104.

23. Shahin R, Kern M. Effect of air-abrasion on the retention of zirconia ceramic crowns luted with different cements before and after artificial aging. Dent Mater 2010;26:922-8.

24. Ali N, Safwat A, Aboushelib M. The effect of fusion sputtering surface treatment on microshear bond strength of zirconia and MDP-containing resin cement. Dent Mater 2019;35:e10712.

25. Güers P, Wille S, Strunskus T, Polonskyi O, Kern M. Durability of resin bonding to zirconia ceramic after contamination and the use of various cleaning methods. Dent Mater 2019;35:138896.

26. Hansen NA, Wille S, Kern M. Effect of reduced airborne-particle abrasion pressure on the retention of zirconia copings resin bonded to titanium abutments. J Prosthet Dent 2020;124:60-7.

27. Amaral R, Ozcan M, Valandro LF, Balducci I, Bottino MA. Effect of conditioning methods on the microtensile bond strength of phosphate monomer-based cement on zirconia ceramic in dry and aged conditions. J Biomed Mater Res B Appl Biomater. 2008;85:1-9.

28. Chen C, Kleverlaan CJ, Feilzer AJ. Effect of an experimental zirconia-silica coating technique on micro tensile bond strength of zirconia in different priming conditions. Dent Mater 2012;28:e127-34.
29. Amaral R, Ozcan M, Bottino MA, Valandro LF. Microtensile bond strength of a resin cement to glass infiltrated zirconiareinforced ceramic: the effect of surface conditioning. Dent Mater 2006;22:283-90.

30. Pazinatto FB, Lopes FA, Marquezini Jr L, de Castro FLA, Atta MT. Effect of surface treatments on the spreading velocity of simplified adhesive systems. J Appl Oral Sci 2006;14:393-8.

31. Yamaguchi H, Ino S, Hamano N, Okada S, Teranaka T. Examination of bond strength and mechanical properties of Y-TZP zirconia ceramics with different surface modifications. Dent Mater J 2012;31:472-80.

32. Cavalcanti AN, Foxton RM, Watson TF, Oliveira MT, Giannini M, Marchi GM. Bond strength of resin cements to a zirconia ceramic with different surface treatments. Oper Dent 2009;34:280-7.

33. Mahmoodi N, Hooshmand T, Heidari S, Khoshro K. Effect of sandblasting, silica coating, and laser treatment on the microtensile bond strength of a dental zirconia ceramic to resin cements. Lasers Med Sci 2016;31:205-11.

34. Braga RR, Meira JB, Boaro LC, Xavier TA. Adhesion to tooth structure: a critical review of "macro" test methods. Dent Mater 2010;26:e38-49. 